\title{
24th Workshop on Logic, Language, Information and Computation-WoLLIC 2017
}

\section{Juliette Kennedy ${ }^{1} \cdot$ Ruy de Queiroz ${ }^{2}$}

Published online: 15 June 2021

(c) The Author(s), under exclusive licence to Springer-Verlag GmbH Germany, part of Springer Nature 2021

\section{Preface}

WoLLIC 2017 was held in London, UK, July 18-21, 2017, in the Department of Computer Science, University College London (UCL).

WoLLIC (http://wollic.org) is a series of workshops which started in 1994 with the aim of fostering interdisciplinary research in pure and applied logic. The idea is to have a forum which is large enough in the number of possible interactions between logic and the sciences related to information and computation, and yet is small enough to allow for concrete and useful interaction among participants. Previous versions were held at: Recife (Pernambuco, Brazil) in 1994 and 1995; Salvador (Bahia, Brazil) in 1996; Fortaleza (Ceará, Brazil) in 1997; São Paulo (Brazil) in 1998; Itatiaia (Rio de Janeiro, Brazil) in 1999; Natal (RN, Brazil) in 2000; Brasília (Distrito Federal, Brazil) in 2001; Rio de Janeiro (Brazil) in 2002; Ouro Preto (Minas Gerais, Brazil) in 2003; Fontainebleau (France) in 2004; Florianópolis (Santa Catarina, Brazil) in 2005; Stanford (California, USA) in 2006; Rio de Janeiro in 2007; Edinburgh in 2008; Tokyo in 2009; Brasília in 2010; Philadelphia in 2011; Buenos Aires in 2012; Darmstadt in 2013; Valparaiso in 2014; Bloomington (IN) in 2015; Puebla in 2016. It is planned that the meeting will take place in: 2018 in Bogotá, 2019 in Utrecht, 2020 (cancelled due to the coronavirus pandemic), 2021 in Virtual Chair.

WoLLIC 2017 once again carried on the tradition of promoting inter-disciplinary and cross-disciplinary research, topics ranging from from mathematical proof theory to formal semantics of natural languages.

Juliette Kennedy

juliette.kennedy@helsinki.fi

Ruy de Queiroz

ruy@cin.ufpe.br

1 Department of Mathematics and Statistics, University of Helsinki, Gustaf Hällströmin katu 2b, P.O. Box 68, 00014 Helsinki, Finland

2 Centro de Informática-Univ Federal de Pernambuco (UFPE), Av. Jornalista Aníbal Fernandes, s/n Cidade Universitária, 50740-560 Recife, PE, Brazil 
The Program Committee consisted of M. Baaz (University of Technology, Vienna, Austria), J. Baldwin (University of Illinois at Chicago, USA), D. Bartozova (Universidade de São Paulo, Brazil), A. Ciabattoni (University of Technology, Vienna, Austria), W. Dean (University of Warwick, UK), E. Grädel (RWTH Aachen, Germany), V. Halbach (University of Oxford, UK), J. Kennedy (Helsinki University, Finland (Chair)), D. Kozen (Cornell University, USA), J. Makowsky (Technion - Israel Institute of Technology, Israel), L. Moss (Indiana University, USA), A. Palmigiano (Delft University, The Netherlands), M. Sadrzadeh (Queen Mary, UK), S. Smets (Amsterdam University, The Netherlands), A. Tornquist (Kobenhavns Universitet, Denmark), R. Verbrugge (University of Groningen, The Netherlands), A. Villaveces (Universidad Nacional, Colombia), Ph. Welch (University of Bristol, UK).

The Organizing Committee members were: J. Brotherston (UCL), P. Oliva (Queen Mary), A. G. de Oliveira (U Fed Pernambuco), R. de Queiroz (U Fed Pernambuco) (co-chair) A. Silva (UCL) (Local co-chair), M. Sadrzadeh (Queen Mary) (Local cochair).

As in previous instances, WoLLIC 2017 included invited talks as well as contributed papers. The Program Committee received 61 submissions. A thorough review process by the program committee, assisted by a number of external reviewers, has led to the acceptance of 23 papers for presentation at the meeting and inclusion in the Proceedings which was published as volume 10388 of Springer's Lecture Notes in Computer Science (FoLLI subseries). The conference program also included two tutorial lectures and 8 invited talks by 8 prominent invited speakers, who have graciously accepted the program committee's invitation:

1. Hazel Brickhill (Bristol) (University of Bristol): A New Way to Measure Subsets of Ordinals: Generalised Closed Unbounded and Stationary Sets.

2. Michael Detlefsen (University of Notre Dame): Formalism: Historical and Conceptual Background.

3. Alexander Kurz (University of Leicester): Coalgebraic Logic.

4. Frederike Moltmann (New York University): Natural Language Metaphysics.

5. David Pym (University College London): Resource Semantics: Logic as a Modelling Technology.

6. Nicole Schweikardt (Humboldt Universität): Database Query Answering under Updates.

7. Fan Yang (Delft University): Characterizing dependencies in logic and sciences.

8. Boris Zilber (University of Oxford): Positive model theory and approximation by finite structures.

There were also four tutorials given by Michael Detlefsen, Alexander Kurz, Frederike Moltmann, and Nicole Schweikardt.

The full papers published in this special issue were selected from the list of papers presented at the meeting, and they have all undergone an independent round of peer reviewing. At the moment of announcing the call for extended versions, there was a warning that for the paper to be considered for publication, it was expected that the journal version would have to be a significant extension of the paper published in the proceedings of the meeting. 
Special session: screening of films about mathematicians. On the evening of Thursday July 20th, as a tribute to a recent project which focus on the cross-cultural connections that are made through mathematics and the impact that Navajo Math Circles can have on a community, there was a screening of George Csicsery's Navajo Math Circles (2016), a one-hour film, documenting the process of a two year period in which hundreds of Navajo children in recent years have found themselves at the center of a lively collaboration with mathematicians from around the world.

We are grateful to the many people who contributed to the success of the meeting and to this special issue: Program Committee members, invited speakers, and authors and presenters of contributed papers; the external reviewers who often provided detailed and highly valuable feedback; the hard-working Organizing Committee in London; and the referees of the papers invited to the special issue.

On behalf of the entire WoLLIC community, we also express our gratitude to our institutional sponsors and supporters. We acknowledge the generous financial support provided by University College London as well as the scientific sponsorship of the following organizations: Association for Symbolic Logic (ASL), Interest Group in Pure and Applied Logics (IGPL), Association for Logic, Language and Information (FoLLI), the European Association for Theoretical Computer Science (EATCS), the Sociedade Brasileira de Computação (SBC), and the Sociedade Brasileira de Lógica $(S B L)$.

Juliette Kennedy and Ruy de Queiroz

Publisher's Note Springer Nature remains neutral with regard to jurisdictional claims in published maps and institutional affiliations. 